\title{
Developing Eco-Friendly and Cost-Effective Porous Adsorbent for Carbon Dioxide Capture
}

\author{
Mahboubeh Nabavinia ${ }^{1}$, Baishali Kanjilal ${ }^{2}$, Naohiro Fujinuma ${ }^{1}$, Amos Mugweru ${ }^{3}$ and Iman Noshadi ${ }^{1,2, *}$ \\ 1 Department of Chemical Engineering, Rowan University, Glassboro, NJ 08028, USA; \\ nabavinim1@students.rowan.edu (M.N.); fujinuma@rowan.edu (N.F.) \\ 2 Department of Bioengineering, University of California, Riverside, CA 92516, USA; \\ baishali.kanjilal@gmail.com \\ 3 Department of Chemistry, Rowan University, Glassboro, NJ 08028, USA; mugweru@rowan.edu \\ * Correspondence: imann@ucr.edu; Tel.: +1-856-818-6102
}

Citation: Nabavinia, M.; Kanjilal, B.; Fujinuma, N.; Mugweru, A.;

Noshadi, I. Developing Eco-Friendly and Cost-Effective Porous Adsorbent for Carbon Dioxide Capture.

Molecules 2021, 26, 1962. https://

doi.org/10.3390/molecules26071962

Academic Editor: Maurizio Peruzzini

Received: 3 March 2021

Accepted: 20 March 2021

Published: 31 March 2021

Publisher's Note: MDPI stays neutral with regard to jurisdictional claims in published maps and institutional affiliations.

Copyright: (c) 2021 by the authors. Licensee MDPI, Basel, Switzerland. This article is an open access article distributed under the terms and conditions of the Creative Commons Attribution (CC BY) license (https:// creativecommons.org/licenses/by/ $4.0 /)$.

\begin{abstract}
To address the issue of global warming and climate change issues, recent research efforts have highlighted opportunities for capturing and electrochemically converting carbon dioxide $\left(\mathrm{CO}_{2}\right)$. Despite metal doped polymers receiving widespread attention in this respect, the structures hitherto reported lack in ease of synthesis with scale up feasibility. In this study, a series of mesoporous metal-doped polymers (MRFs) with tunable metal functionality and hierarchical porosity were successfully synthesized using a one-step copolymerization of resorcinol and formaldehyde with Polyethyleneimine (PEI) under solvothermal conditions. The effect of PEI and metal doping concentrations were observed on physical properties and adsorption results. The results confirmed the role of PEI on the mesoporosity of the polymer networks and high surface area in addition to enhanced $\mathrm{CO}_{2}$ capture capacity. The resulting Cobalt doped material shows excellent thermal stability and promising $\mathrm{CO}_{2}$ capture performance, with equilibrium adsorption of $2.3 \mathrm{mmol}$ $\mathrm{CO}_{2} / \mathrm{g}$ at $0{ }^{\circ} \mathrm{C}$ and $1 \mathrm{bar}$ for at a surface area $675.62 \mathrm{~m}^{2} / \mathrm{g}$. This mesoporous polymer, with its ease of synthesis is a promising candidate for promising for $\mathrm{CO}_{2}$ capture and possible subsequent electrochemical conversion.
\end{abstract}

Keywords: carbon dioxide; capture; mesoporous polymer; cobalt; nickel

\section{Introduction}

With a significant rise in the average atmospheric $\mathrm{CO}_{2}$ concentration from levels in the preindustrial age, deleterious effects on global warming and climate change have become visible [1-3]. Consequently, environmental concerns have convinced international bodies and governments to take steps to address policies pertaining to $\mathrm{CO}_{2}$ emissions. Some of the most remarkable strategies are $\mathrm{CO}_{2}$ capturing and conversion technologies, such as chemical, photocatalytic [4,5], and electrocatalytic reduction [6-8], for which the first step is efficient $\mathrm{CO}_{2}$ capture. In many of these technologies, heterogenous conversion catalysts, function [9-11], in the first step as, solid adsorbents and some of these entail materials such as silica [12-14], metal-organic frame (MOFs) [3], and carbon-based materials [14-17]. Some commonly researched carbon-based adsorbent materials entail activated carbon [18], ordered mesoporous polymer/carbon (OMP/OMC) [14,19,20], activated carbon fibers [21,22], graphene [2,17], and graphene oxide [23-25]. Regular pore structure, high surface area, and inexpensive precursors proffer potential advantages in OMP/OMC for $\mathrm{CO}_{2}$ capture $[14,19,20]$. The primary bottleneck in designing a feasible and cost-effective carbon capture and conversion process lies in producing a highly efficient carbo capture porous structure which also proffers feasibility of eco-friendly process scale-up along with high capture capacity, in addition to being retrofittable to sustainably convert $\mathrm{CO}_{2}$ to chemicals and fuels $[1,26,27]$. In several works, adsorption capacity and activity of adsorbents has been enhanced using functionalization of the catalyst surface and pore lining $[14,20,28]$. 
The basicity of nitrogenous functional groups, such as amines, provide sites for enhanced interactions with acidic $\mathrm{CO}_{2}$. Thus, doping via functionalization with basic nitrogen containing groups is considered as the most attractive methods to capture $\mathrm{CO}_{2}[22,26,29]$. Fujian et al. showed that nitrogen not only increased $\mathrm{CO}_{2}$ capture but also made anchoring metal elements to polymer network feasible [20]. They synthesized an ordered mesoporous phenol- formaldehyde polymer by using hexamethylenetetramine (HMTA) as a source of nitrogen. These structures exhibited high stability, $\mathrm{CO}_{2}$ capture capacity and selectivity [20]. The anchoring of a transition metal to this framework also makes it probable to speculate its possible application as a $\mathrm{CO}_{2}$ conversion catalyst, provided a high enough $\mathrm{CO}_{2}$ capture capacity can be ensured.

Polyethylenimine (PEI) is a multipurpose polymer with amine-containing repeat units, spaced out by the aliphatic ethylene $\mathrm{CH}_{2} \mathrm{CH}_{2}$ ligand [30]. Due to its high basicity, high amine content, good thermal stability, and low volatility it can be used to produce highly effective and stable functionalized adsorbents [31,32]. Silica [33,34], nanocarbon tube, ordered mesoporous carbon, polymer [31,35] and alumina [36] have been studied with PEI modifications. PEI functionalized Polymethyl methacrylate (PMMA), and polystyrene (PS) [35] showed high $\mathrm{CO}_{2}$ adsorption capacity. Even though these structures have shown high $\mathrm{CO}_{2}$ capture capacities their commercial application has not been realized yet. The main hindrance to their commercial application is complicated, multi-stage synthesis method. This not only increases the cost of adsorbent, but also puts significant limitations on the scalability [31,37]. To overcome this, Wang et al. have developed organic aminemediated synthesis of polymers for $\mathrm{CO}_{2}$ capturing and energy storage [38].

Solid metal-doped polymers are considered effective and environment-friendly catalyst for carbon dioxide conversion. Their advantageous features include high surface area, thermal stability, and good activity [2]. MOFs have also been reported as good adsorbents and catalysts owing to the active metal sites [3]. Cobalt, zinc, and nickel have been extensively used for this purpose. In addition to enhanced $\mathrm{CO}_{2}$ capture, these metals also facilitate photo or chemical-electro conversion. The solvothermal method is a common method for metal impregnation into heterogeneous structures which these compounds use to modify organic frame for improving capture and entrapment of $\mathrm{CO}_{2}$ and its possible subsequent conversion $[2,3]$. The elimination of multistep catalyst synthesis can pave way to realizable scale-up and hence commercial application.

This paper focuses on the potential of nitrogen-doped mesoporous polymer (MRF), made using PEI, with and without a metal center. The MRFs have been studied for $\mathrm{CO}_{2}$ capturing for possibility subsequent electrochemical conversion. In this paper, we studied cobalt and nickel doped MR. The effect of metal and PEI concentration on MRF properties such as surface area, pore size, pore structures and morphology, thermal stability were studied. For the synthetic procedure we used resorcinol and formaldehyde as precursors. Contrary to multi-stage synthesis, the one-pot solvothermal method not only decreases the cost of production by practically eliminating the use of high solvent volumes, it also eliminates scale- up barriers. In addition, low temperature of synthesis without the calcination stage makes it an ecofriendly process. The MRFs exhibit superior surface area and a uniform mesoporous structure, as observed from scanning electron microscopy. The elemental analysis map confirmed homogenous metal distribution. This approach also provides the opportunity for producing multi metal centered catalyst structures.

\section{Results}

\subsection{Chemical Structure and Thermal Stability}

The results of elemental analysis, on various compositions, is presented in Table 1. EDS elemental analysis of these compositions is illustrated in Supplementary Materials Figures S1 and S2. Elemental mapping results, as shown in Table 1, confirm that an increase in PEI concentration corresponded to an increase nitrogen content. Figures S1 and S2 underscore uniformity of distribution of cobalt and nickel in the test sample. PEI plays an important role in developing a uniform mesoporous structure. Nitrogen is indicative of the 
presence of the amine group of the branched PEI structure. The presence of nitrogen helps to increase nanoporosity by tethering to the Co or Ni nucleation centers while participating in the crosslinking kinetics on the other. While the nitrogen content in H-RF is expected to be double that of M-RF, it may be assumed that some of the excess PEI remains adsorbed in the porous structure leading to the inordinately high nitrogen content as seen in Table 1. The additional affinity of $\mathrm{Ni}$ to the PEI nitrogen can be assumed to assumed play a part in affecting the porous structure of the formed MRFs and this is discussed in some detail in a later section. The incorporation of Co with progressively increasing content in reaction mixture is quite representative of the expected ratios of incorporation. In the Ni3-M-RF, the experimental results show that there is only $0.7 \mathrm{wt} \%$ of $\mathrm{Ni}$.

Table 1. Elemental analysis of various catalyst compositions (all figures in \%weight).

\begin{tabular}{cccccc}
\hline Sample & Carbon & Oxygen & Nitrogen & Cobalt & Nickel \\
\hline RF & 62.6 & 31.4 & 0 & 0 & 0 \\
M-RF & 77.6 & 20.1 & 2.3 & 0 & 0 \\
H-RF & 60.7 & 28.9 & 10.4 & 0 & 0 \\
Co1-M-RF & 60.9 & 31.3 & 7.4 & 0.4 & 0 \\
Co3-M-RF & 51.9 & 37.8 & 9.0 & 1.3 & 0 \\
Ni3-M-RF & 73.2 & 23.4 & 2.7 & 0 & 0.7 \\
Co5-M-RF & 54.67 & 37.12 & 5.42 & 2.79 & 0 \\
Co3-H-RF & 63.9 & 33.3 & 2.0 & 0.8 & 0 \\
\hline
\end{tabular}

Fourier transform infrared (FTIR) spectra was used to characterize the chemical structures of synthesized N-OMPs and these are shown in Figure 1a-d. While Figure 1a shows the spectrum of a general resorcinol formaldehyde resin, Figure $1 \mathrm{~b}$ shows the FTIR spectra of the MRF made with 1.96\% PEI. In Figure 1c (Co3-M-RF), the spectra of MRF with $1.96 \%$ PEI and $1.3 \%$ Co is shown as an example, while Figure $1 \mathrm{~d}$ (Ni3-M-RF) shows the corresponding resin with $0.7 \% \mathrm{Ni}$. The change in the positions of the characteristic peaks with a change of the metal type at the center of the complex is insignificant. This points to the fact that there is very little difference in the bonding characteristic with the metal center. In the FTIR spectra, characteristic peaks associated with phenolic resins are observed. These entail absorption bands of benzene rings at $800-900 \mathrm{~cm}^{-1}$, the bending vibration of the $\mathrm{C}-\mathrm{O}$ bond at $1157 \mathrm{~cm}^{-1}$, the absorption band of the methyl group at $1219 \mathrm{~cm}^{-1}$, the absorption bands of the methylene bridge at 1445 and $2827-2963 \mathrm{~cm}^{-1}$, and the stretching vibration of the $\mathrm{O}-\mathrm{H}$ bond at $3200-3400 \mathrm{~cm}^{-1}$. Besides, the characteristic peaks associated with nitrogen species are also observed. These entail the stretching vibration of the C-N bond at $1110 \mathrm{~cm}^{-1}$, the bending vibration of the $\mathrm{N}-\mathrm{H}$ bond at $1605 \mathrm{~cm}^{-1}$, and the stretching vibration of the $\mathrm{N}-\mathrm{H}$ bond at $3400-3500 \mathrm{~cm}^{-1}$.

The thermal stability of the MRFs was evaluated via thermal analysis by heating the samples in an inert atmosphere. To remove moisture, the samples were warm up to $10{ }^{\circ} \mathrm{C}$ and then the weight loss measurement started at $50^{\circ} \mathrm{C}$ to $600^{\circ} \mathrm{C}$ under a constant nitrogen flow rate. The various compositions differed substantially in their thermal stability profiles and this is shown in Figure 1d-f. Thermal stability of RF is slightly better than M-RF as seen in Figure 1d. It could be construed that the presence of the amine functionality causes a more rapid breakdown of the polymeric structure with temperature due to a catalytic action. The thermal stability of 3\% Co is superior to both that containing $1 \%$ and $5 \%$ Cobalt contents. The MRF with while Co3-M-RF showed more thermal stability compared to a composition containing nickel as the metal center. 

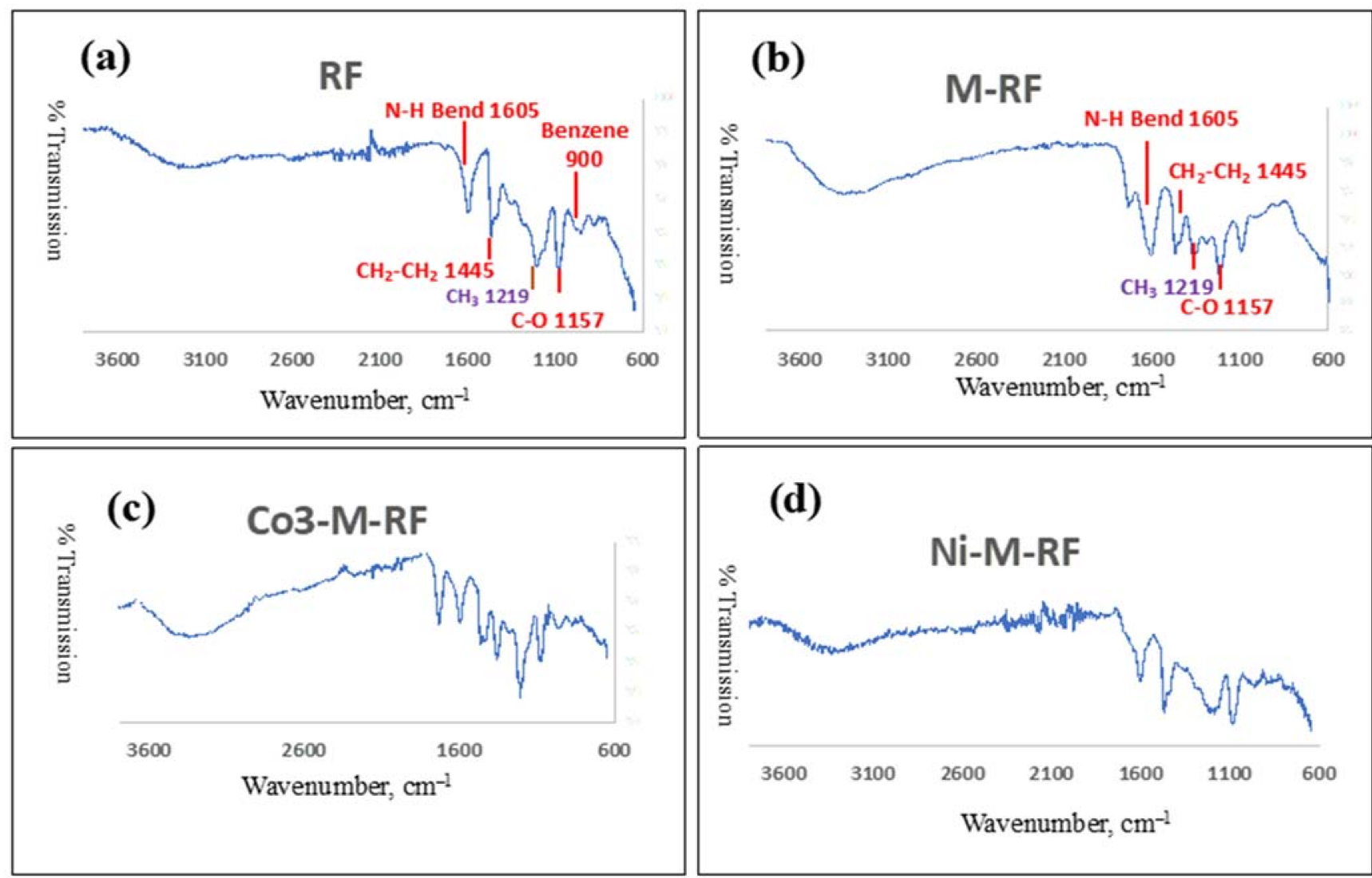

\section{(d)}
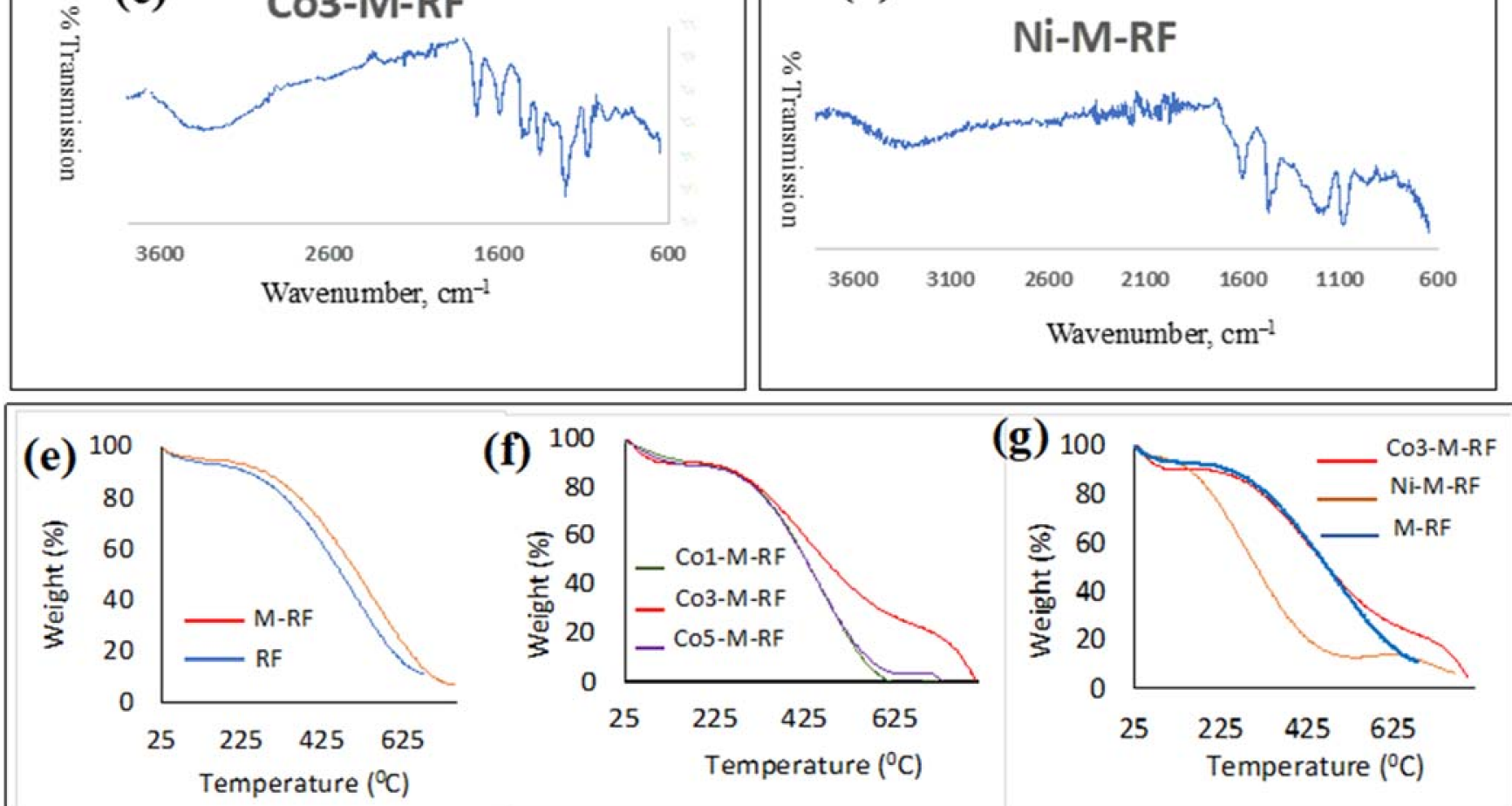

Figure 1. FTIR spectra (a) RF resin (b) Mesoporous catalyst without metal centers (c) MRF with 3\%Co (Co2-M-RF) (d) MRF with Ni (Ni3-M-RF), Thermogravimetric Analysis (e) RF and MRF without metal centers (f) MRF with progressively increasing Co content (g) Comparison of MRF with MRF-3\% Co and MRF with Ni.

\subsection{Surface Area and Pore Structure}

The nitrogen adsorption/desorption isotherms were obtained by NOVA Tech at $76 \mathrm{~K}$ and plotted in Figure 2. The surface area for all samples was calculated by multipoint BET model based on adsorption plot and showed in Table 2 . The detailed porosity parameters of pore size volume and diameter were calculated by BJH model and are summarized in this table. Varying the concentrations of PEI, cobalt, and metal salt has a visible influence on the textural and surface morphologies of the MRFs. The porosity can be significantly improved by varying the PEI and cobalt concentrations, however the effect is not linearly correlated to their concentration. 
a

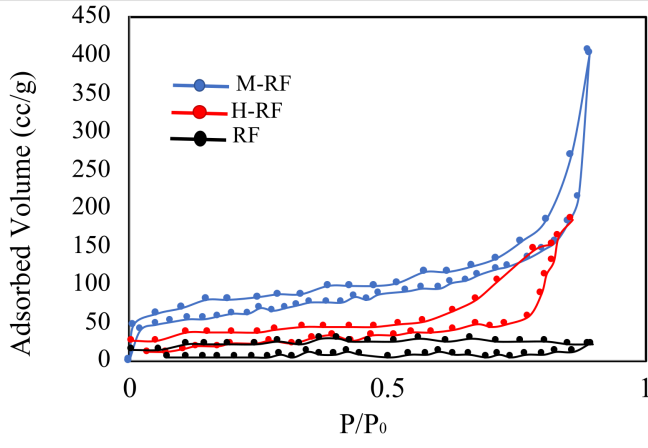

C

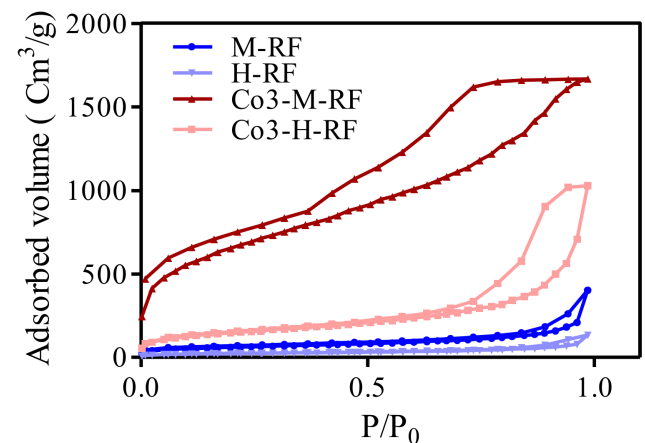

b

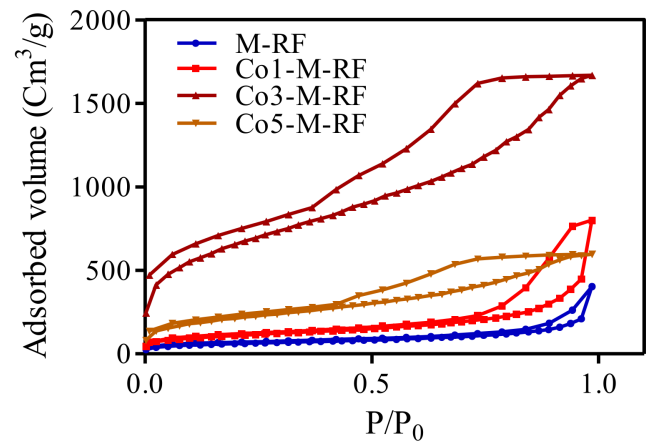

$\mathrm{d}$

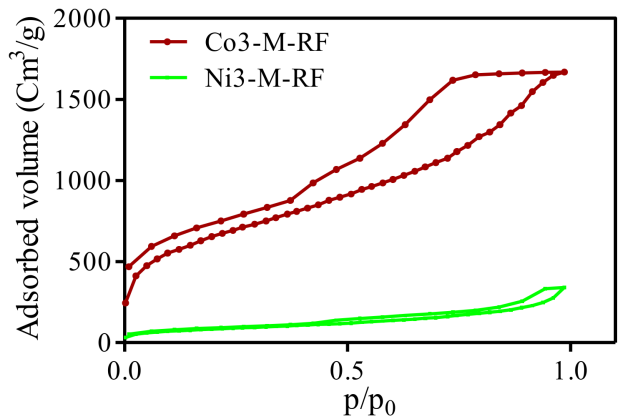

Figure 2. $\mathrm{N}_{2}$ adsorption/desorption isotherms of (a) RF with varying PEI concentration ( $0 \%, 1.96 \%$ and $3.98 \%$ by weight), (b) MRFs with varying cobalt concentrations ( $0 \%, 1 \%, 3 \%$ and $5 \%$ Co (III) acetylacetonate by weight, (c) Cobalt doped RF made with varying PEI (1.96\% and 3.98\%) and Cobalt concentration $(0 \%, 3 \%$ and $5 \% \mathrm{Co}(\mathrm{III})$ acetylacetonate by weight), and (d) Metal -doped M-RF with 3\% Co (III) acetylacetonate by weight and 3\% Ni(II) acetylacetonate by weight.

Table 2. Surface area and pore size distributions of various catalyst based on BJH model. (Standard deviation was within $( \pm 3-4 \%)$ of the average values).

\begin{tabular}{|c|c|c|c|c|}
\hline \multirow{2}{*}{ Sample } & \multirow{2}{*}{$\begin{array}{c}\text { BET Data } \\
\text { Surface Area } \\
\left(\mathrm{m}^{2} / \mathrm{g}\right)\end{array}$} & \multicolumn{3}{|c|}{ Mesoporous Based on BJH Model } \\
\hline & & $\begin{array}{c}\text { Surface Area } \\
\qquad\left(\mathrm{m}^{2} / \mathrm{g}\right)\end{array}$ & $\begin{array}{l}\text { Pore Volume } \\
\qquad\left(\mathrm{cm}^{3} / \mathrm{g}\right)\end{array}$ & $\begin{array}{c}\text { Pore Size } \\
\text { Radius (nm) }\end{array}$ \\
\hline RF & 19.67 & 13.53 & 0.041 & \\
\hline M-RF & 325.99 & 207.01 & 0.35 & 1.62 \\
\hline H-RF & 212.13 & 80.07 & 0.34 & 2.39 \\
\hline Co1-M-RF & 220.12 & 108.11 & 1.14 & 1.99 \\
\hline Co3-RF & 149.80 & 149.80 & 0.25 & 1.89 \\
\hline Co3-M-RF & 977.11 & 226.09 & 1.83 & \\
\hline Co3-H-RF & 342.22 & 123.29 & 0.15 & \\
\hline Co5-M-RF & 375.19 & 98.73 & 0.71 & 1.53 \\
\hline Ni3-M-RF & 264.82 & 87.08 & 0.20 & 1.69 \\
\hline
\end{tabular}

Increasing PEI concentration, as seen in the metal-free mesoporous polymers, from $0 \%(\mathrm{RF})$ to a content of $1.96 \%$ (M-RF) increases the BET surface area from $19.67 \mathrm{~m}^{2} / \mathrm{g}$ to $325.99 \mathrm{~m}^{2} / \mathrm{g}$. A further increase in the PEI content to $3.98 \%$ (H-RF) decreases it to $212.13 \mathrm{~cm}^{3} / \mathrm{g}$. This is shown in Figure 2a. As per the stoichiometry of RF-PEI network formation reaction, any amount of PEI that is beyond limit of crosslinking, determined by relative component stoichiometries, will simply remain unreacted. This unreacted PEI enter the pores of the mesoporous crosslinked network in the form of a liquid and blocks them. This in turn reduces available surface area and is reflected in the BET experiment.

The results of $\mathrm{N}_{2}$ adsorption/desorption isotherms are shown in Figure 2a-d. With $3 \%$ Cobalt doping in the MRF containing 1.96\% PEI, the BET surface area is seen to increase to $977.111 \mathrm{~m}^{2} / \mathrm{g}$. This composition is designated as Co3-M-RF. With $1 \%$ Co the BET surface area decreases significantly. With a much higher $5 \%$ Co doping there is an insignificant change in surface area compared to the undoped MRF structure as well as that of Co3-M-RF. The surface area increases much faster with Cobalt doping in the 
MRF made with medium PEI, MRF (1.96\%) than that made with higher amounts of PEI, HRF ( $3 \%$ doping). With M-RF, for the Co3-M-RF composition, the surface area by more than $200 \%$ over an undoped samples. While with a higher PEI loading (H-RF), the same amount of Co increases the surface area by only $61.3 \%$. The doping using Co may be thought to induce a morphological nucleation of the polymer which, in tandem with the crosslinking kinetics forms an optimized structure with the maximum possible surface area. The nucleation and cross-linking have their own kinetic rates which appear to be experimentally optimized at 3\% Co content, neither lower, nor higher percentage of Co doping see to have obtained the same optimization to maximization of surface area and this is seen in Figure 2b. In Figure 2c, the significantly higher surface area of the polymer with $3 \%$ Co and $1.96 \%$ PEI, merely underscores the points made above of the optimized level of Co and PEI incorporation to achieve the best possible results. The shape of the curves correlates very closely to type IV isotherms that are typical in mesoporous solids. The adsorption on mesoporous solids occurs vis multilayer adsorption which is followed by capillary condensation that leads to the hysteresis loop as is seen in the figures. The capillary condensation that takes place in the mesopores can somewhat limit uptake at higher partial pressures. However, in the case of RF, the obtained isotherm showed Type $\mathrm{IV}$ and $\mathrm{V}$ indicating a greater predominance of capillary condensation.

The SEM images of various MRFs was illustrated in Figure $3 a-h$, confirmed uniform microporosity of samples contained PEI. The SEM images reflect the results and observations in the figure and table above. The spherical morphology of RF (Figure 3a) is another proof for the importance of PEI in developing a uniform morphology with an interconnected framework, which can be seen in subsequent images. The immobilization of cobalt increases pore interconnection with consequent enhancement in surface area, as mentioned above. It is obvious that excessive incorporation of either PEI or Co destroys the clean morphology that is obtained with $1.96 \%$ PEI and $3 \% \mathrm{Co}$, which again is testament to the empirically obtained optimization of the nucleation and crosslinking reactions. The SEM images also affirm that $\mathrm{Ni}$ (Figure $3 \mathrm{~h}$ ) is not as effective in inducing the morphological optimization as is seen with Co doping.
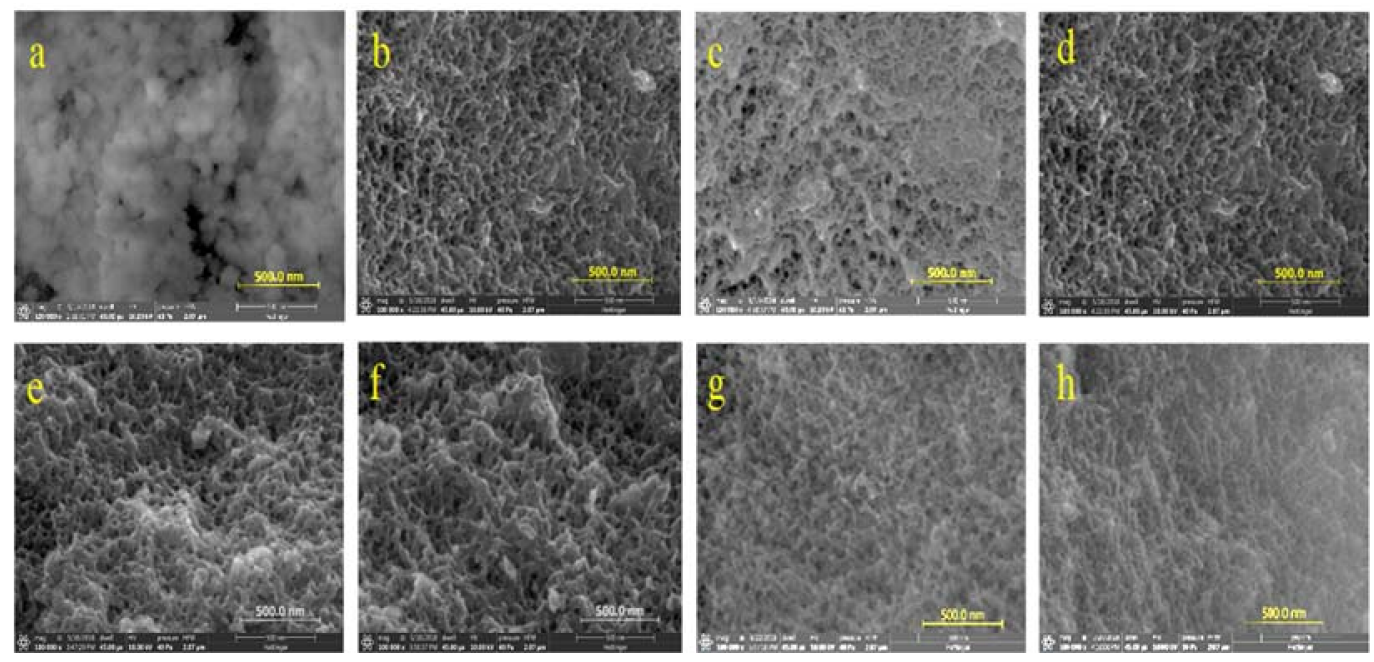

Figure 3. SEM of various samples: (a) RF (b) M-RF (c) Co1-M-RF (d) Co3-M-RF (e) Co5-M-RF(f) Co3-H-RF (g) H-RF (h) Ni3-RF.

\subsection{Carbon Dioxide Adsorption}

The carbon dioxide adsorption results are presented in Figure 4a-f. The MRFs were utilized as adsorbents for $\mathrm{CO}_{2}$ adsorption at $25^{\circ} \mathrm{C}$ or $0{ }^{\circ} \mathrm{C}$ and 1 bar. $\mathrm{CO}_{2}$ adsorption isotherms of MRFs are shown in Figure 4a,d. The $\mathrm{CO}_{2}$ uptake at 1 bar is presented Figure $4 \mathrm{~b}, \mathrm{c}, \mathrm{e}, \mathrm{f}$. 

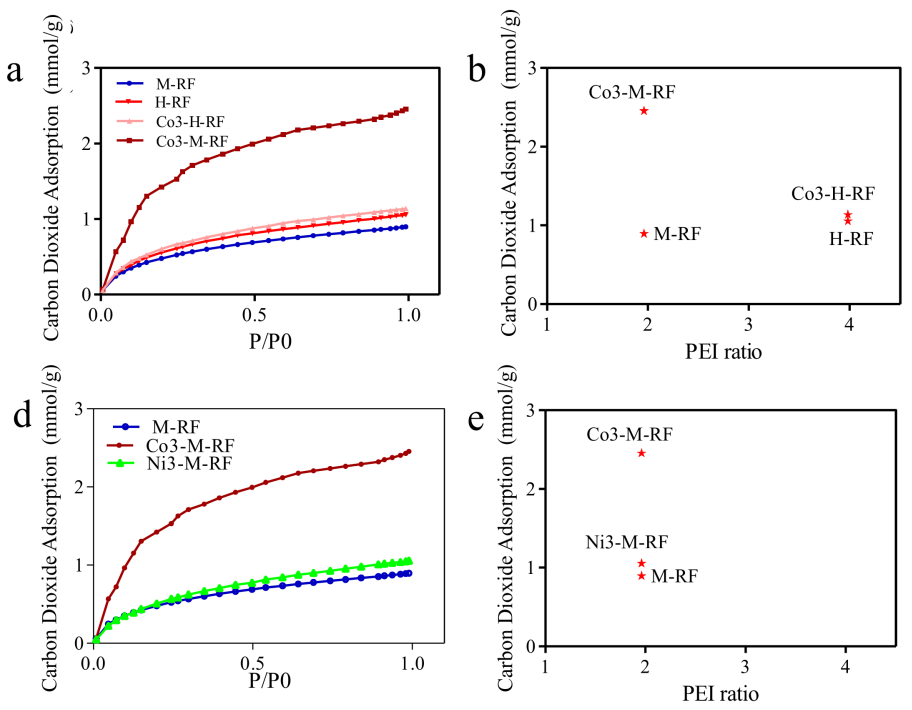

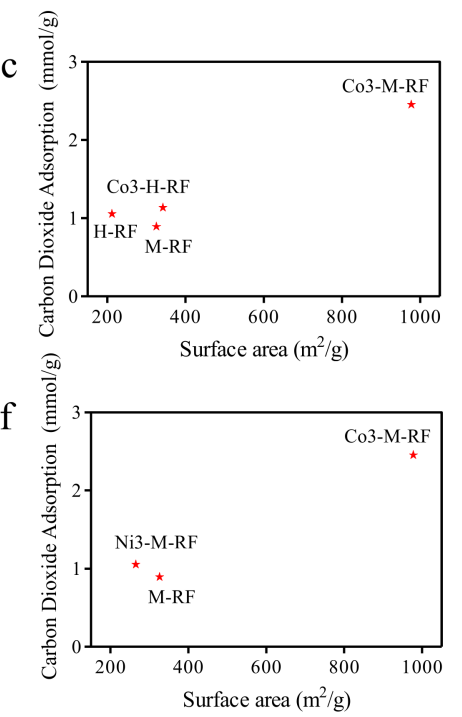

Figure 4. Carbon dioxide adsorption of various composition (a) at $0{ }^{\circ} \mathrm{C}$, vs. $\mathrm{P} / \mathrm{P}_{0}(\mathbf{b}) \cdot \mathrm{CO}_{2}$ adsorption at $0{ }^{\circ} \mathrm{C}$ vs. $\mathrm{PEI} \%$ weight in $\mathrm{MRF}$ (c) $\mathrm{CO}_{2}$ adsorption at $0{ }^{\circ} \mathrm{C}$ vs. Surface area (d) Carbon absorption at $25^{\circ} \mathrm{C}$ vs. $\mathrm{P} / \mathrm{P}_{0}\left(\right.$ e) $\mathrm{CO}_{2}$ adsorption at $25^{\circ} \mathrm{C}$ vs. PEI \% weight in MRF (f) $\mathrm{CO}_{2}$ adsorption at $25^{\circ} \mathrm{C}$ vs. Surface area.

The adsorption results with Co3-M-RF shows the best adsorption results. One primary reason is that the surface areas of this sample was seen to be higher than other samples. The high PEI containing samples perhaps had quite a bit of the pores blocked by the presence of excess PEI in liquid form blocking gaseous movement through the mesopores and hence its subsequent adsorption. The is reflected in Figure $4 \mathrm{~b}$. A higher PEI content is expected to attract more $\mathrm{CO}_{2}$ due to its alkaline disposition. However, the reality remains that the compositions with higher PEI content result in lower surface area due to unreacted PEI plugging pores and hence causes diminished adsorption. The adsorption of $\mathrm{CO}_{2}$ is a balance between the amount of surface area proffered and the alkalinity of the surface area functionality. The importance of surface area available for adsorption is underscored in Figure $4 \mathrm{c}$ where the composition with the higher surface area adsorbs the higher amount of $\mathrm{CO}_{2}$ despite having lower content of PEI compared to H-RF structures. M-RF, which has a low surface area $\left(325.99 \mathrm{~m}^{2} \cdot \mathrm{g}^{-1}\right)$ and pore volume $\left(0.35 \mathrm{~cm}^{3} \cdot \mathrm{g}^{-1}\right)$, exhibits a $\mathrm{CO}_{2}$ uptake of $1.15 \mathrm{mmol} \cdot \mathrm{g}^{-1}$. The Cobalt doped sample Co3-M-RF also shows a high $\mathrm{CO}_{2}$ adsorption capacity ( $2.5 \mathrm{mmol} \cdot \mathrm{g}^{-1}$ at ${ }^{\circ} \mathrm{C}$ and $1 \mathrm{bar}$ ). Ni3-M-RF displays a $\mathrm{CO}_{2}$ adsorption capacity of $1.05 \mathrm{mmol} \cdot \mathrm{g}^{-1}$ at $0^{\circ} \mathrm{C}, 1 \mathrm{bar}$. Previous research demonstrates that resorcinol-formaldehyde resin exhibit stronger Lewis basicity, and generally have good $\mathrm{CO}_{2}$ capture capabilities on their own. Here we see that the $\mathrm{CO}_{2}$ capture capability rises when a doping metal center is introduced. In Figure 4e,f, despite comparable amount of PEI, the sample with cobalt doping has superior $\mathrm{CO}_{2}$ adsorption because it has a much higher surface area. When the concentration of PEI is increased from 0 to $3.98 \%$, there is very little concomitant increase in $\mathrm{CO}_{2}$ adsorption. However, an increase in cobalt concentration, caused the $\mathrm{CO}_{2}$ adsorption to be enhanced sharply. Thus, it is seen that doping causes a significant effect on nucleation and hence formation of mesopores and channels thereof, increasing the surface area, which plays a greater role in the adsorption efficiency than that proffered by the functional alkalinity obtained from higher PEI functionalization.

\section{Discussion}

Higher content of PEI in a mesoporous RF resin structure, leads to more rapid carbonization of the polymer network resulting in a sharp and rapid weight loss. Additionally, PEI is thought to attract moisture and further speed up breakdown of benzoxazine connectors with increasing temperature. This trend is reflected in the TGA results. Samples containing Cobalt as the doing center have more thermal stability compared to those containing Nickel. Nickel is known to exhibit greater bonding to PEI nitrogen atoms entailing 
the coordination of a donor heteroatom with an electro-deficient metal center. The lone pair of electrons on nitrogen atoms in the PEI structure form a donor complex with Nickel, causing an ensuing catalytic effect. Thus, the thermal degradation of the Nickel doped MRFs is more rapid compared to Cobalt nucleated MRFs $[39,40]$.

Co has a more pronounced effect in increasing surface area than Ni. This is seen clearly in the polymer made with $1.96 \%$ PEI and shown in Figure $2 \mathrm{~d}$. While both Cobalt and Nickel have six coordination sites each, Nickel is known to have a higher affinity for amino coordination, as seen in polyhistidine tag chromatography [40]. The weaker affinity of Cobalt has been seen in protein chromatography. It results in Co being less deleterious on the structure of the protein by way of lower bonding affinity. A similar process is thought to occur in the polymers made in this work. Here, morphological nucleation works alongside and parallel to the cross-linking process in the polymeric structure. We can visualize the lone pair of electrons on the PEI amine nitrogen coordinate with the Ni vacant orbitals. This coordination complex based anchoring results in a nucleation process which competes with the rate of crosslinking. Thus, a higher affinity with Ni may cause a more pronounced disruptive effect on structure formation and porosity.

A milder coordination between PEI amine lone electron pairs and the Cobalt centers causes a more even balance between crosslinking and nucleation leading to a better development of surface area and uniform porosity [41,42]. The isotherm was found to match to Type IV adsorption curves, indicating the presence of multilayers. However, in the case of $\mathrm{RF}$, the obtained isotherm showed Type IV and V.

\section{Materials and Methods}

\subsection{Materials}

Resorcinol (99\%), Formaldehyde solution (37\% in water), and branched polyethylenimine (MW = 10000) were purchased from Alfa Aesar (Haverhill, MA, USA) and used without any further processing. Cobalt acetylacetonate and nickel acetylacetonate (95\%) were obtained from Bean Town Chemicals (Hudson, NH, USA) and used as received. Ethanol proof 200 (VWR) and sodium hydrogen sulfate were purchased from SigmaAldrich (St. Louis, MO, USA).

\subsection{Synthesis of $M y-x-R F s$}

My-x-RFs were synthesized by a one-pot solvothermal method. $1.5 \mathrm{~g}$ resorcinol was dissolved in $4.4 \mathrm{~mL}$ of deionized water (DI). Then $5.6 \mathrm{~mL}$ of PEI $(1.96 \%$ or $3.98 \%) w / v$ in ethanol was added, and the mixture was kept stirring at $40{ }^{\circ} \mathrm{C}$ for $20 \mathrm{~min}$. Then the metal salt was added and stirred for an addition $20 \mathrm{~min}$ at $40^{\circ} \mathrm{C}$. Then $2.1 \mathrm{~mL}$ of formaldehyde solution $37 \%$ was injected by syringe quickly and the milky solution stirred at high speed for $20 \mathrm{~min}$ at $40^{\circ} \mathrm{C}$. Finally, this emulsion was transferred to a Teflon autoclave chamber and kept a under static condition at $120^{\circ} \mathrm{C}$ for $12 \mathrm{~h}$. After cooling to room temperature, the polymer was smashed and washed three times with water and then three times by ethanol. M-RFs were dried at room temperature overnight. The obtained mesoporous catalyst was named as My-x-RFs, where $\mathrm{M}$ is metal type, $\mathrm{y}$ is metal concentration in the reaction mixture, and $x$ is the PEI concentration denoted as $\mathrm{N}(0 \% \mathrm{PEI}), \mathrm{M}(1.96 \% \mathrm{PEI})$ and $\mathrm{H}(3.98 \% \mathrm{PEI})$. RF is denoted for mesoporous resorcinol formaldehyde polymer without metal salt and PEI.

\subsection{Characterization}

Scanning electron microscope (SEM) was used to look at the morphology and pore structure of the samples. Thermo Scientific ${ }^{\mathrm{TM}}$ FEI Quanta ${ }^{\mathrm{TM}}$ line 650 SEM (Waltham, MA, USA) with a low vacuum detector under $10 \mathrm{kV}$ took images. Then energy-Dispersive Spectroscopy (EDS) was used for elemental mapping analysis by FEI Quanta FEG 250 detector. Aztec software (Oxford Instruments, Abdington, UK) was applied to the analysis of EDS data. Thermogravimetric analyzer (TG) was performed on TA Instruments Q500 with $10{ }^{\circ} \mathrm{C} \cdot \mathrm{min}^{-1}$ to $750{ }^{\circ} \mathrm{C}$ under $\mathrm{N}_{2}$ with $100 \mathrm{~m}^{2} / \mathrm{hr}$. To remove moisture from the 
samples, temperature was increased to $100^{\circ} \mathrm{C}$, and data acquisition was started after cooling down to $50{ }^{\circ} \mathrm{C}$. The $\mathrm{N}_{2}$ Adsorption was measured by Quantachrome NOVA Tech LX4. Prior the measurement, the sample was degassed at $120^{\circ} \mathrm{C}$ for $24 \mathrm{~h}$ under vacuum to remove the adsorbed species on the surface of sample and finally cooled to room temperature. The Brunauer-Emmett-Teller (BET) method was utilized to calculate the specific mesoporous surface area of the samples by using the adsorption branch acquired at a relative pressure $\left(\mathrm{P} / \mathrm{P}_{0}\right)$ range of $0.05-0.30$ (Equation (1)). Barrett, Joyner, and Halenda $(\mathrm{BJH})$ model was applied to estimate pore size volume from the quantity of $\mathrm{N}_{2}$ adsorbed at relative pressure $\left(\mathrm{P} / \mathrm{P}_{\mathrm{O}}\right)$ of 0.99 . Touch Win ${ }^{\mathrm{TM}}$ software was used for all calculation which was reported in Table 1.

$$
\frac{1}{W\left(\left(\frac{P_{0}}{p}\right)-1\right)}=\left(\frac{1}{W_{m} C}\right)+\frac{C-1}{\left(W_{m} C\right)}\left(\frac{P}{P_{0}}\right)
$$

where $\mathrm{W}$ is the weight of gas adsorbed at a relative pressure, $\mathrm{P} / \mathrm{P}_{0}$, and $\mathrm{W}_{\mathrm{m}}$ is the weight of adsorbate constituting a monolayer of surface coverage, and C "Constant", is related to the energy of adsorption in the first adsorbed layer and consequently its value is an indication of the magnitude or strength of the adsorbent/adsorbate interactions.

Molecular structure of the samples was explored by Fourier transform infrared spectroscopy (FT-IR). IR spectra were recorded on a PerkinElmer Spectrum 100 FT-IR spectrometer.

\subsection{Carbon Dioxide Adsorption}

$\mathrm{CO}_{2}$ adsorption was measured by the same system (Quantachrome NOVA Tech LX4) up to 1 bar, but ice bath was used for $0^{\circ} \mathrm{C}$ and water bath for room temperature experiments. The samples were degassed as mentioned above. The isosteric heat of adsorption (Qst) was calculated based on the Clausius-Clapeyron equation [43] for which the $\mathrm{CO}_{2}$ adsorption was conducted at two different temperatures of 273 and $298 \mathrm{~K}$ by Equation (2).

$$
\text { Qst }=\mathrm{RT}^{2}\left(\frac{\partial \operatorname{Ln} \mathrm{p}}{\operatorname{Ln} \mathrm{T}}\right)
$$

where $\mathrm{R}$ is universal gas constant; $\mathrm{T}_{2}$ and $\mathrm{T}_{1}$ are two different temperatures based on Kelvin; $\mathrm{P}_{2}$ and $\mathrm{P}_{1}$ are the partial pressure at the same amount of adsorbed $\mathrm{CO}_{2}$ for $\mathrm{T}_{2}$ and $\mathrm{T}_{1}$.

\section{Conclusions}

In summary, this paper presented a novel, template-free and generalized method, for the fast and scalable synthesis of metal centered mesoporous polymer for $\mathrm{CO}_{2}$ capturing for its possible subsequent conversion by metal catalyzed electrochemical reduction. The presented method can strongly promote the industrial application of mesoporous polymer by overcoming a series of process and scale up limitation associated with the traditional template-based self-assembly route. Owing to an abundant nitrogen content, high alkaline functionality, and predominantly mesoporous nature, the synthesized MRFs demonstrated excellent capacity for $\mathrm{CO}_{2}$ adsorption. Based on these results, it can be concluded that a combination of metal functionality and mesoporosity is very important for $\mathrm{CO}_{2}$ adsorption and catalytic conversion of $\mathrm{CO}_{2}$. Thus, this work provides an initial novel insight for the designing porous materials with high performance for the selective capture and conversion of $\mathrm{CO}_{2}$ from flue gas. The FTIR results, SEM, and elemental analysis validated the incorporation of different kinds and contents of nitrogen species into the framework synthesized MRFs. The nitrogen adsorption isotherms and SEM images revealed that the synthesized MRFs have large surface areas and abundant meso-macropores. The $\mathrm{CO}_{2}$ and $\mathrm{N}_{2}$ adsorption experiments demonstrated that the synthesized MRFs have high capacity for $\mathrm{CO}_{2}$ at a relatively low pressure of $0.15 \mathrm{bar}\left(0.64-1.47 \mathrm{mmol} \cdot \mathrm{g}^{-1}\right.$ at $0{ }^{\circ} \mathrm{C}$ and $0.49-0.87 \mathrm{mmol} \cdot \mathrm{g}^{-1}$ at $25^{\circ} \mathrm{C}$ ). This work provides a facile approach to the targeted synthesis of nitrogen functionalized MRFs with potential applications in the s capture and electrochemical conversion of $\mathrm{CO}_{2}$. 
Supplementary Materials: The following are available online, Figure S1: EDS elemental analysis of various samples: (a) RF (b) M-RF (c) H-RF, Figure S2: EDS elemental analysis of various samples: (d) Co1-M-RF (e) Co3-M-RF (f) Co5-M-RF (g) Ni3-M-RF.

Author Contributions: Conceptualization, M.N., I.N.; Methodology, M.N., I.N.; Formal Analysis, M.N., I.N.; Investigation, M.N., I.N.; Resources, I.N.; Data Curation, M.N., I.N.; Writing-original draft preparation, M.N., I.N.; Writing—review and editing, M.N., I.N., B.K., A.M., N.F.; Visualization, M.N.; Supervision, I.N.; Project Administration, I.N.; Funding Acquisition, I.N. All authors have read and agreed to the published version of the manuscript.

Funding: This research was funded by Rowan University Startup Fund (Fund No. 11010).

Data Availability Statement: Data is contained within the article or supplementary material.

Acknowledgments: The authors also appreciate Jeffrey Hettinger for the assistance on SEM and EDAX characterization of the samples.

Conflicts of Interest: The authors declare no conflict of interest.

Sample Availability: Samples of the compounds Co1-M-RF, Co3-M-RF, Co5-M-RF, Ni3-M-RF are available from the authors.

\section{References}

1. Oh, T.H. Carbon capture and storage potential in coal-fired plant in Malaysia-A review. Renew. Sustain. Energy Rev. 2010, 14, 2697-2709. [CrossRef]

2. Liu, X.; Zhu, L.; Wang, H.; He, G.; Bian, Z. Catalysis performance comparison for electrochemical reduction of $\mathrm{CO}_{2}$ on $\mathrm{Pd}_{-}$ $\mathrm{Cu}$ /graphene catalyst. RSC Adv. 2016, 6, 38380-38387. [CrossRef]

3. Maina, J.W.; Pozo-Gonzalo, C.; Kong, L.; Schütz, J.; Hill, M.; Dumée, L.F. Metal organic framework based catalysts for CO 2 conversion. Mater. Horiz. 2017, 4, 345-361. [CrossRef]

4. Yaashikaa, P.; Kumar, P.S.; Varjani, S.J.; Saravanan, A. A review on photochemical, biochemical and electrochemical transformation of $\mathrm{CO}_{2}$ into value-added products. J. CO2 Util. 2019, 33, 131-147. [CrossRef]

5. Chen, C.S.; Handoko, A.D.; Wan, J.H.; Ma, L.; Ren, D.; Yeo, S. Stable and Selective Electrochemical Reduction of Carbon Dioxide to Ethylene on Copper Mesocrystals Article Type Stable and Selective Electrochemical Reduction of Carbon Dioxide to Ethylene on Copper Mesocrystals. Catal. Sci. Technol. 2015, 5, 161-168. [CrossRef]

6. Zhao, C.; Wang, J. Electrochemical reduction of $\mathrm{CO}_{2}$ to formate in aqueous solution using electro-deposited Sn catalysts. Chem. Eng. J. 2016, 293, 161-170. [CrossRef]

7. Zhang, T.; Li, X.; Qiu, Y.; Su, P.; Xu, W.; Zhong, H.; Zhang, H. Multilayered Zn nanosheets as an electrocatalyst for efficient electrochemical reduction of $\mathrm{CO}_{2}$. J. Catal. 2018, 357, 154-162. [CrossRef]

8. Han, N.; Wang, Y.; Ma, L.; Wen, J.; Li, J.; Zheng, H.; Nie, K.; Wang, X.; Zhao, F.; Li, Y.; et al. Supported Cobalt Polyphthalocyanine for High-Performance Electrocatalytic $\mathrm{CO}_{2}$ Reduction. Chem 2017, 3, 652-664. [CrossRef]

9. Castro-Osma, J.A.; North, M.; Wu, X. Synthesis of Cyclic Carbonates Catalysed by Chromium and Aluminium Salphen Complexes. Chem. Eur. J. 2016, 22, 2100-2107. [CrossRef]

10. Buttner, H.; Longwitz, L.; Steinbauer, J.; Wulf, C.; Werner, T. Recent Developments in the Synthesis of Cyclic Carbonates from Epoxides and $\mathrm{CO}_{2}$ Top. Curr. Chem. 2017, 375, 50.

11. Janeta, M.; Lis, T.; Szafert, S. Zinc Imine Polyhedral Oligomeric Silsesquioxane as a Quattro-Site Catalyst for the Synthesis of Cyclic Carbonates from Epoxides and Low-Pressure $\mathrm{CO}_{2}$. Chem. Eur. J. 2020, 26, 13686-13697. [CrossRef] [PubMed]

12. Tang, Q.; Wang, Y.; Zhang, J.; Qiao, R.; Xie, X.; Wang, Y.; Yang, Y. Cobalt(II) acetylacetonate complex immobilized on aminosilanemodified SBA-15 as an efficient catalyst for epoxidation of trans-stilbene with molecular oxygen. Appl. Organomet. Chem. 2016, 30, 435-440. [CrossRef]

13. Hu, X.-M.; Hval, H.H.; Bjerglund, E.T.; Dalgaard, K.J.; Madsen, M.R.; Pohl, M.-M.; Welter, E.; Lamagni, P.; Buhl, K.B.; Bremholm, M.; et al. Selective $\mathrm{CO}_{2}$ Reduction to $\mathrm{CO}$ in Water using Earth-Abundant Metal and Nitrogen-Doped Carbon Electrocatalysts. ACS Catal. 2018, 8, 6255-6264. [CrossRef]

14. Yu, J.; Guo, M.; Muhammad, F.; Wang, A.; Zhang, F.; Li, Q.; Zhu, G. One-pot synthesis of highly ordered nitrogen-containing mesoporous carbon with resorcinol-urea-formaldehyde resin for $\mathrm{CO}_{2}$ capture. Carbon 2014, 69, 502-514. [CrossRef]

15. Chen, Z.; Deng, S.; Wei, H.; Wang, B.; Huang, J.; Yu, G. Polyethylenimine-Impregnated Resin for High $\mathrm{CO}_{2}$ Adsorption: An Efficient Adsorbent for $\mathrm{CO}_{2}$ Capture from Simulated Flue Gas and Ambient Air. ACS Appl. Mater. Interfaces 2013, 5, 6937-6945. [CrossRef]

16. Adelodun, A.A.; Kim, K.-H.; Ngila, J.C.; Szulejko, J. A review on the effect of amination pretreatment for the selective separation of $\mathrm{CO}_{2}$. Appl. Energy 2015, 158, 631-642. [CrossRef]

17. Ma, T.; Fan, Q.; Li, X.; Qiu, J.; Wu, T.; Sun, Z. Graphene-based materials for electrochemical $\mathrm{CO}_{2}$ reduction. J. CO2 Util. 2019, 30, 168-182. [CrossRef] 
18. Sethia, G.; Sayari, A. Comprehensive study of ultra-microporous nitrogen-doped activated carbon for $\mathrm{CO}_{2}$ capture. Carbon 2015, 93, 68-80. [CrossRef]

19. Liu, Z.; Du, Z.; Song, H.; Wang, C.; Subhan, F.; Xing, W.; Yan, Z. The fabrication of porous N-doped carbon from widely available urea formaldehyde resin for carbon dioxide adsorption. J. Colloid Interface Sci. 2014, 416, 124-132. [CrossRef]

20. Liu, F.; Huang, K.; Wu, Q.; Dai, S. Solvent-Free Self-Assembly to the Synthesis of Nitrogen-Doped Ordered Mesoporous Polymers for Highly Selective Capture and Conversion of $\mathrm{CO}_{2}$. Adv. Mater. 2017, 29, 1700445. [CrossRef]

21. Thostenson, E.T.; Li, W.Z.; Wang, D.Z.; Ren, Z.F.; Chou, T.W. Carbon nanotube/carbon fiber hybrid multiscale composites. J. Appl. Phys. 2002, 91, 6034-6037. [CrossRef]

22. Chiang, Y.-C.; Hsu, W.-L.; Lin, S.-Y.; Juang, R.-S. Enhanced $\mathrm{CO}_{2}$ Adsorption on Activated Carbon Fibers Grafted with NitrogenDoped Carbon Nanotubes. Materials 2017, 10, 511. [CrossRef] [PubMed]

23. Razmkhah, M.; Mosavian, M.T.H.; Moosavi, F.; Ahmadpour, $\mathrm{A}$. $\mathrm{CO}_{2}$ gas adsorption into graphene oxide framework: Effect of electric and magnetic field. Appl. Surf. Sci. 2018, 456, 318-327. [CrossRef]

24. Zhang, Y.; Chi, Y.; Zhao, C.; Liu, Y.; Zhao, Y.; Jiang, L.; Song, Y. $\mathrm{CO}_{2}$ Adsorption Behavior of Graphite Oxide Modified with Tetraethylenepentamine. J. Chem. Eng. Data 2017, 63, 202-207. [CrossRef]

25. Kemp, K.C.; Chandra, V.; Saleh, M.; Kim, K.S. Reversible $\mathrm{CO}_{2}$ adsorption by an activated nitrogen doped graphene/polyaniline material. Nanotechnology 2013, 24, 235703. [CrossRef]

26. Ju, H.; Kaur, G.; Kulkarni, A.P.; Giddey, S. Challenges and trends in developing technology for electrochemically reducing $\mathrm{CO}_{2}$ in solid polymer electrolyte membrane reactors. J. CO2 Util. 2019, 32, 178-186. [CrossRef]

27. Olajire, A.A. Recent progress on the nanoparticles-assisted greenhouse carbon dioxide conversion processes. J. CO2 Util. 2018, 24, 522-547. [CrossRef]

28. Sun, Y.; Li, K.; Zhao, J.; Wang, J.; Tang, N.; Zhang, D.; Guan, T.; Jin, Z. Nitrogen and sulfur Co-doped microporous activated carbon macro-spheres for $\mathrm{CO}_{2}$ capture. J. Colloid Interface Sci. 2018, 526, 174-183. [CrossRef] [PubMed]

29. Jin, Z.-E.; Wang, J.-L.; Zhao, R.-J.; Guan, T.-T.; Zhang, D.-D.; Li, K.-X. Synthesis of S, N co-doped porous carbons from polybenzoxazine for $\mathrm{CO}_{2}$ capture. New Carbon Mater. 2018, 33, 392-401. [CrossRef]

30. Liu, F.; Huang, K.; Yoo, C.-J.; Okonkwo, C.; Tao, D.-J.; Jones, C.W.; Dai, S. Facilely synthesized meso-macroporous polymer as support of poly(ethyleneimine) for highly efficient and selective capture of $\mathrm{CO}_{2}$. Chem. Eng. J. 2017, 314, 466-476. [CrossRef]

31. Niu, M.; Yang, H.; Zhang, X.; Wang, Y.; Tang, A. Amine-Impregnated Mesoporous Silica Nanotube as an Emerging Nanocomposite for CO2 Capture. ACS Appl. Mater. Interfaces 2016, 8, 17312-17320. [CrossRef]

32. Li, P.; Ge, B.; Zhang, S.; Chen, S.; Zhang, Q.; Zhao, Y. $\mathrm{CO}_{2}$ Capture by Polyethylenimine-Modified Fibrous Adsorbent. Langmuir 2008, 24, 6567-6574. [CrossRef]

33. Yan, X.; Zhang, L.; Zhang, Y.; Qiao, K.; Yan, Z.; Komarneni, S. Amine-modified mesocellular silica foams for $\mathrm{CO}_{2}$ capture. Chem. Eng. J. 2011, 168, 918-924. [CrossRef]

34. Subagyono, D.J.; Marshall, M.; Knowles, G.P.; Chaffee, A.L. $\mathrm{CO}_{2}$ adsorption by amine modified siliceous mesostructured cellular foam (MCF) in humidified gas. Micropor. Mesopor. Mater. 2014, 186, 84-93. [CrossRef]

35. Gray, M.L.; Hoffman, J.S.; Hreha, D.C.; Fauth, D.J.; Hedges, S.W.; Champagne, K.J.; Pennline, H.W. Parametric Study of Solid Amine Sorbents for the Capture of Carbon Dioxide. Energy Fuels 2009, 23, 4840-4844. [CrossRef]

36. Sakwa-Novak, M.A.; Yoo, C.-J.; Tan, S.; Rashidi, F.; Jones, C.W. Poly(ethylenimine)-Functionalized Monolithic Alumina Honeycomb Adsorbents for CO2Capture from Air. Chem. Sus. Chem. 2016, 9, 1859-1868. [CrossRef]

37. Dindi, A.; Quang, D.V.; Nashef, E.; Abu Zahra, M.R. Effect of PEI Impregnation on the $\mathrm{CO}_{2}$ Capture Performance of Activated Fly Ash. Energy Procedia 2017, 114, 2243-2251. [CrossRef]

38. Wang, J.; Yao, L.; Ma, C.; Guo, X.; Qiao, W.; Ling, L.; Long, D. Organic Amine-Mediated Synthesis of Polymer and Carbon Microspheres: Mechanism Insight and Energy-Related Applications. ACS Appl. Mater. Interfaces 2016, 8, 4851-4861. [CrossRef]

39. Min, K.; Choi, W.; Kim, C.; Choi, M. Oxidation-stable amine-containing adsorbents for carbon dioxide capture. Nat. Commun. 2018, 9, 1-7. [CrossRef]

40. Huan, L.; Shi, Y.; Chen, L.; Jin, X.; Liu, R.; Winnik, M.A.; Mitchell, D. Thermal decomposition of amide and imide derivatives of malleated polyethylene. J. Polym. Sci. Part A Polym. Chem. 2000, 38, 730-740. [CrossRef]

41. Krämer, U.; Cotter-Howells, J.D.; Charnock, J.M.; Baker, A.J.M.; Smith, J.A.C. Free histidine as a metal chelator in plants that accumulate nickel. Nature 1996, 379, 635-638. [CrossRef]

42. Wegner, S.V.; Spatz, J.P. Cobalt(III) as a Stable and Inert Mediator Ion between NTA and His6-Tagged Proteins. Angew. Chem. Int. Ed. 2013, 52, 7593-7596. [CrossRef]

43. Newalkar, B.L.; Choudary, N.V.; Kumar, P.; Komarneni, S.; Bhat, T.S.G. Exploring the Potential of Mesoporous Silica, SBA-15, as an Adsorbent for Light Hydrocarbon Separation. Chem. Mater. 2002, 14, 304-309. [CrossRef] 